\title{
Determination of Genotoxic Pollution of Some Hospital Wastewater with Salmonella Ames Test
}

\author{
Ali Rıza Atasoy ${ }^{1 *}$, Engin Karakece ${ }^{2}$, Mustafa Petek ${ }^{3}$, Lokman Alpsoy $^{3}$, Abdullah Kiran ${ }^{4}$ \\ ${ }^{1}$ Department of Microbiology, Faculty of Medicine, Sakarya University, Sakarya, Turkey \\ ${ }^{2}$ Microbiology Laboratory, Sakarya Education and Research Hospital, Sakarya, Turkey \\ ${ }^{3}$ Institute of Science and Engineering, Fatih University, Istanbul, Turkey \\ ${ }^{4}$ Saruhanlı Food Vocational School, Celal Bayar University, Manisa, Turkey \\ Email: *aratasoy@sakarya.edu.tr
}

Received August 6, 2012; revised September 3, 2012; accepted October 1, 2012

\begin{abstract}
Wastewater of hospitals contains materials that would be a threat to alive. These water needs to be checked by a biological purification before leaving to nature. Hospital wastewater has differences than domestic waste because of especially blood, body waste, drugs, chemicals, medical device waste and radioactive materials. We aimed to determine genotoxic effects of total pollution in hospital wastewater on alive by Salmonella microsome test method. In this study, we decided on three hospitals which weren't checked as biological purification of waste. The samples were taken for six 1-week periods between March 2009 and June 2009. Mutagenite studies of samples taken from hospitals were made with Salmonella typhimurium TA 98 and TA 100. Wastewater samples were evaporated. 27 different test materials were prepared using DMSO, ethanol and acetone solvents, two different MGA plaques were used for each test material. Each experiment was made for 3 times with known results of mutagens and we made it ready for "Ames" test method. We had genotoxicity 50\% in Istanbul University Medical Faculty Hospital, 56\% in Haseki Hospital and 61\% in Vakıf Gureba Hospital. According to three hospitals result there are 9 positives, 9 negatives in DMSO; 9 positives, 9 negatives in ethanol; 12 positives, 6 negatives in acetone. These values are totally 56\%. Our results give important information about mutagenic effect of total pollution in hospital wastewater. It is first time researched in Turkey that effect on DNA of pollution is from hospital wastewaters. In prospective studies, it is necessary to use this system as a method to monitor mutagenic genotoxic pollution in hospital wastewaters. These kinds of studies present applicability and importance of our method because of placing in the literature. Method constitutes a new approach to check mutagenite of pollution in hospital wastewater.
\end{abstract}

Keywords: Hospital Wastewater; Ames Test; TA 98; TA 100; Genotoxicity

\section{Introduction}

Medical waste is a byproduct of healthcare that includes blood, chemicals, body parts, pharmaceuticals, medical devices, and radioactive materials. Poor management of health care waste may expose healthcare personal, waste handlers, and the community to infectious agents, to toxic materials. Medical waste material causes a large portion of the diseases that develop due to poor waste management. Waste containing chemical substances e.g., laboratory chemicals, empty bottles of lab or pharmacy chemicals, disinfectants that have expired or are no longer needed; solvents, diagnostic kits, poisonous and corrosive materials, and cleaning agents and others. Unused liquids from radiotherapy or laboratory research; contaminated glassware, packages, or absorbent paper; urine and excreta from patients treated or tested with unsealed radio nucleotides; sealed sources. Hospitals rep-

*Corresponding author. resent an incontestable release source of many chemicals compounds in the aquatic environment due to laboratory activity or medicine excretion into wastewater [1].

Some of the substances found in wastewaters are genotoxic and are suspected to be a possible cause of the cancers observed in the last decades. Water genotoxicity studies are of interest because epidemiologic investigations have shown a link between genotoxic drinking water intake and a rise in cancers [2]. The results of these studies must, however, be interpreted with caution because the exposure to genotoxic water was only estimated and not really measured. However, these results emphasized the importance of the determination of water genotoxicity with an aim at controlling the population exposure. Thus, the monitoring of water contamination for potentially carcinogenic compounds represents a major concern for human health. It is extremely difficult to quantify the risk associated with these chemical pollutants because they usually occur in concentrations too low 
to allow analytical determination, and putative mutagens, with few exceptions, have never even been identified.

These kinds of studies are used in order to confirm mutagenic effect of total pollution of different sources on alives or to investigate pollutions that come from only one source [3-8] or to investigate materials that is possible to have mutagenic effects $([9,10])$.

In this study we aimed to determine genotoxic effects of total pollution in hospital wastewater on alive by Salmonella microsome test method. This study is researched first time in Turkey that effect on DNA of pollution that is got from water samples from hospital wastewaters.

\section{Materials and Methods}

\subsection{Sample Preparation}

There are only few studies dealing with the hospital wastewater genotoxicity [8,11-14]. Even if no standard followed protocols for sample collection, sample processing, or selection of tests exist, and all the studies show that the hospital wastewater could have a nontoxic potential.

The samples collected from Bezm-i Alem Valide Sultan Vakıf Gureba Training and Research Hospital, Haseki Training and Research Hospital, Istanbul University Medical Faculty (Capa Hospital). Hospitals were very close and their sewage water goes to same purifier.

All samples collected three times to detect mutagenic pollutants on living organisms. The samples were taken for six 1-week periods between March 2009 and June 2009. Mutagenite studies of samples taken from hospitals were made 3 times for 2 petri plaques for each sample with TA 98 and TA 100. 27 different test materials and DMSO, ethanol and acetone were prepared after waste water samples that are taken from hospitals were evaporated. 2 different MGA plaques were used for each test material. Each experiment was made for 3 times.

The Salmonella strains used in the test have different mutations in various genes in the histidine operon; each of these mutations is designed to be responsive to mutagens that act via different mechanisms. Additional mutations were engineered into these strains to make them more sensitive to a wide variety of substances. S. typhimurium TA 98 and TA 100 strains are used on Salmonella/microsome mutagenite test system.

\subsection{Control of Genetic Specialities of Strains}

It was checked that test strains have original mutations or not according to safety of Salmonella/micro some mutajenite test system. The His character of the tester strains is confirmed by demonstrating the histidine requirement for growth on selective agar plates, Biotin is also required by all of the standard tester strains because of the $u v r B$ deletion which extends through the bio gene.

Colonies that sensation characteristic was corrected before were tested according to resistance for amphisiline. The R-factor strains (TA 97, TA 98, TA 100 and TA 102) should be tested routinely for the presence of the ampicillin resistance factor because the plasmid is somewhat unstable and can be lost from the bacteria [15]. Specific regions of the pKMlOl DNA that are essential for enhancement of UV and chemical mutagenesis, replication, and ampicillin resistance have been identified [16]. $0,1 \mathrm{ml}$ Samples that were got from night cultures of test strains spread to plaques with nutrient agar for control of RFA mutation. Disks that have $10 \mu \mathrm{l}$ crystal violet solution $(1 \mathrm{mg} / \mathrm{ml})$ were placed to the middle of plaques. $u v r B$ mutation avaibility was checked with sensation test to ultraviolet beams. Samples that were got with nightie were planted as an only one colony. Only one colony that increases after one night was planted to two plaques by line test method. Test strains revert ant by itself that causes to increase in situation without histidine was measured as routine on mutajenite experiments and it was mentioned one each plaque as number of bacteria that revertant. Colonies of these bacteria can be seen easily over a plant that shows a regular distribution. Each test strain reverts with a distinctive frequency. In order to find cytotoxic values for bacteria of samples that were kept $-20^{\circ} \mathrm{C}$ in deepfreeze, samples that were prepared as 0.1 acceptable bacteria culture and most $0.1 \mathrm{ml}$ were added. Colony count was made after plaques were incubated for one night in $37^{\circ} \mathrm{C}$ [17].

\subsection{Expression of the Genotoxicity Results}

In Salmonella micro some test system, it is necessary colony number to be double at least to call a material as mutagen. In order to simplify the reading of the results we have classified the intensity of the genotoxic response in three categories according to the tested concentration and the significance level of the response. The three categories are: slightly (G1), moderately (G2) and strongly (G3) genotoxic. We used SPSS 16.0, Independent- Samples $\mathrm{T}$ test method for control of data.

\section{Result}

Generally samples that are solved in acetone more genotoxic than other in TA 98 and samples that are solved in ethanol more genotoxic than other in TA 100. Mutagenite results of solvents with DMSO, ethanol and acetone is given on Table 1. Average value of 6 values for each sample, standart deviation was found. Revertant colony numbers results for positive mutagens (Sodium Azide (1.5 microgram/plague)): TA 98, $178 \pm 32$ and TA $100,2348 \pm 132$ [18].

We examine result of 3 hospitals: 
Table 1. Genotoxicity range and average revertant colony result of samples and control group.

\begin{tabular}{|c|c|c|c|c|c|c|c|c|c|c|c|c|}
\hline \multirow{3}{*}{$\begin{array}{l}\text { Hosp- } \\
\text { itals }\end{array}$} & \multicolumn{6}{|c|}{ TA 98} & \multicolumn{6}{|c|}{ TA 100} \\
\hline & \multicolumn{2}{|c|}{ DMSO } & \multicolumn{2}{|c|}{ ETHANOL } & \multicolumn{2}{|c|}{ ACETONE } & \multicolumn{2}{|c|}{ DMSO } & \multicolumn{2}{|c|}{ ETHANOL } & \multicolumn{2}{|c|}{ ACETONE } \\
\hline & $\begin{array}{c}\text { Genotoxicity } \\
\text { range }\end{array}$ & Average & $\begin{array}{c}\text { Genotoxicity } \\
\text { range }\end{array}$ & Average & $\begin{array}{l}\text { Genotoxicity } \\
\text { Range }\end{array}$ & Average & $\begin{array}{c}\text { Genotoxicity } \\
\text { range }\end{array}$ & Average & $\begin{array}{c}\text { Genotoxicity } \\
\text { range }\end{array}$ & Average & $\begin{array}{c}\text { Genotoxicity } \\
\text { range }\end{array}$ & Average \\
\hline & \multicolumn{12}{|c|}{ MARCH } \\
\hline 1 & $47-63$ & 54.83 & $49-63$ & 46.33 & $50-70$ & 74.5 & $262-326$ & 290.16 & $302-374$ & 291 & $256-352$ & 310.5 \\
\hline 2 & $47-63$ & 66 & $49-63$ & 63.16 & $50-70$ & 54.5 & $262-326$ & 318 & $302-374$ & 344.66 & $256-352$ & 189.3 \\
\hline 3 & $47-63$ & 39.33 & $49-63$ & 59.33 & $50-70$ & 70.8 & $262-326$ & 254.33 & 302 - 374 & 388.66 & $256-352$ & 274.1 \\
\hline 4 & & 27.5 & & 27.83 & & 30.16 & & 147 & & 168.83 & & 152.1 \\
\hline \multicolumn{13}{|c|}{ MAY } \\
\hline 1 & $50-74$ & 38.83 & $46-74$ & 40.16 & $52-72$ & 57 & $255-323$ & 217 & $300-356$ & 187.5 & $267-327$ & 301.6 \\
\hline 2 & $50-74$ & 42.83 & $46-74$ & 39.33 & $52-72$ & 49 & $255-323$ & 165.66 & $300-356$ & 187.5 & $267-327$ & 264.1 \\
\hline 3 & $50-74$ & 61.4 & $46-74$ & 51.83 & $52-72$ & 61.83 & $255-323$ & 351 & $300-356$ & 302.16 & $267-327$ & 421.5 \\
\hline 4 & & 30.83 & & 30.33 & & 30.66 & & 144.5 & & 163.83 & & 148.5 \\
\hline \multicolumn{13}{|c|}{ JUNE } \\
\hline 1 & $56-77$ & 47.83 & $53-73$ & 49.83 & $49-69$ & 44 & $241-333$ & 168.33 & $291-329$ & 310.33 & $272-360$ & 261.5 \\
\hline 2 & $56-77$ & 60.16 & $53-73$ & 28.5 & $49-69$ & 49.16 & $241-333$ & 289.33 & $291-329$ & 281 & $272-360$ & 181 \\
\hline 3 & $56-77$ & 50.5 & $53-73$ & 46.16 & $49-69$ & 42 & $241-333$ & 270.16 & $291-329$ & 271.66 & $272-360$ & 190 \\
\hline 4 & & 33.33 & & 31.5 & & 29 & & 143.5 & & 155.33 & & 157.6 \\
\hline
\end{tabular}

"Hospital: 1) Istanbul University Medical Faculty (Çapa Hospital); 2) Haseki Educational and Research Hospital; 3) Vakıf Gureba Educational and Research Hospital; 4) Control group.

Çapa Hospital: Genotoxicity is found in each 3 solvents in March in this hospital. Values are more on medium and up levels. It has presented mutagenite in wastewater of hospital especially when patient numbers are more and when it is not rainy. In May, it was only seen that mutagenite is available in samples that are solved in acetone. But it is conspicuous that there are many values on limits of mutagenite. In June, mutagenite values are seen only in ethanol. Decrease on number of patients and being close of many values to mutagenite made out this result. Fifty percent genotoxicity is determinated as totally by Ames test.

Haseki Educational and Research Hospital: In all tests that are made in this hospital genotoxicity values are found in all expend one sample. In this sample, down mutagenite is only 3 numbers less than limit with 264. In May is samples that are solved in acetone values that are close to down mutagenite values are found. In June genotocity values are confirmed in samples that are solved in DMSO and acetone. Fifty six percent genotoxicity is determinated as totally by Ames test.

Vakıf Gureba Educational and Research Hospital: In this hospital positive results are obtained in samples that are solved in acetone and ethanol in March. Very close results to 39 and 254 down mutagenite values was obtained in DMSO. All samples were positive in May. Negative results have been obtained expect one sample that is solved in DMSO in June. Sixty one percent genotoxicity is determinated as totally by Ames test. 94\% genotoxicity is determinated as totally by $\mathrm{T}$ test. According to Ames test there are 9 positive, 9 negative in DMSO; 9 positive, 9 negative in ethanol 12 positive, 6 negative in acetone. These values are totally $56 \%$. Genotoxicity results are given Figures 1-3.

Generally results are 50\% in Çapa, 56\% in Haseki and $61 \%$ in Vakıf Gureba. At the same time it is attractive that many values are close to mutagenite value. Especially during counting colonies, there may be same colonies that are escape during counting operation. Results give important information about mutagenic effect of total pollution in hospital wastewater. According to three hospitals result there are 9 positives, 9 negatives in DMSO; 9 positives, 9 negatives in ethanol; 12 positives, 6 negatives in acetone. These values are totally $56 \%$. General 


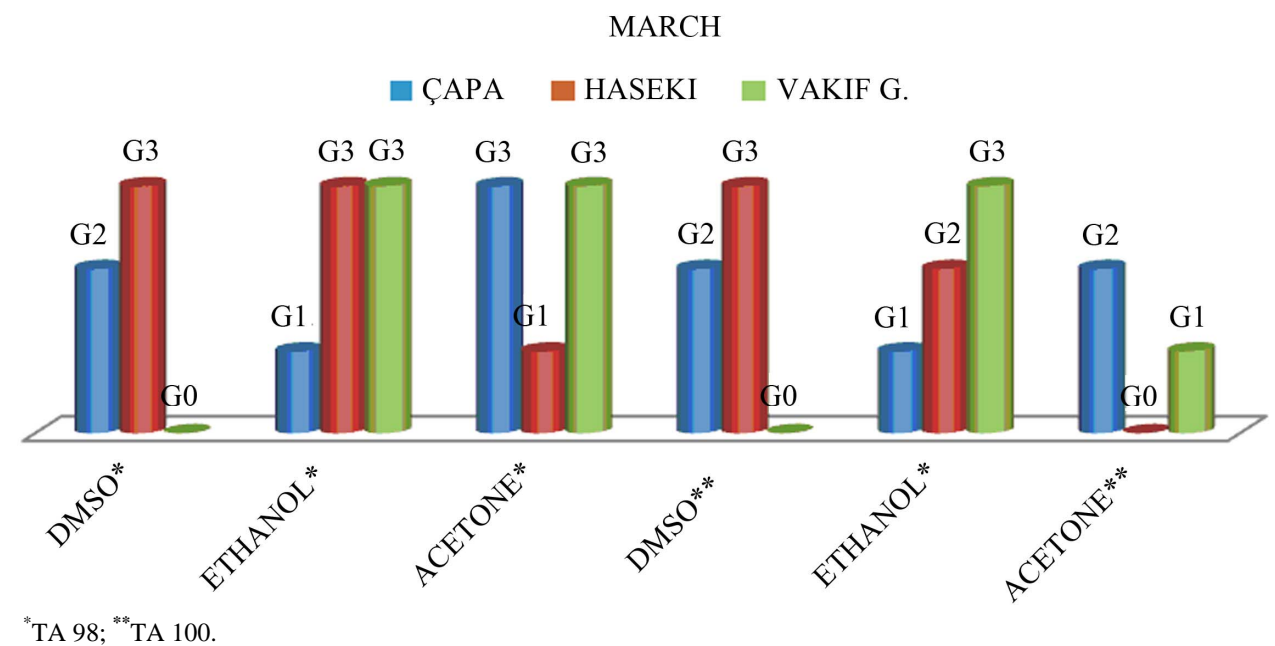

Figure 1. Genotoxicity results in March (G0, not genotoxic; G1, slightly genotoxic; G2, moderately genotoxic; G3, strongly genotoxic).

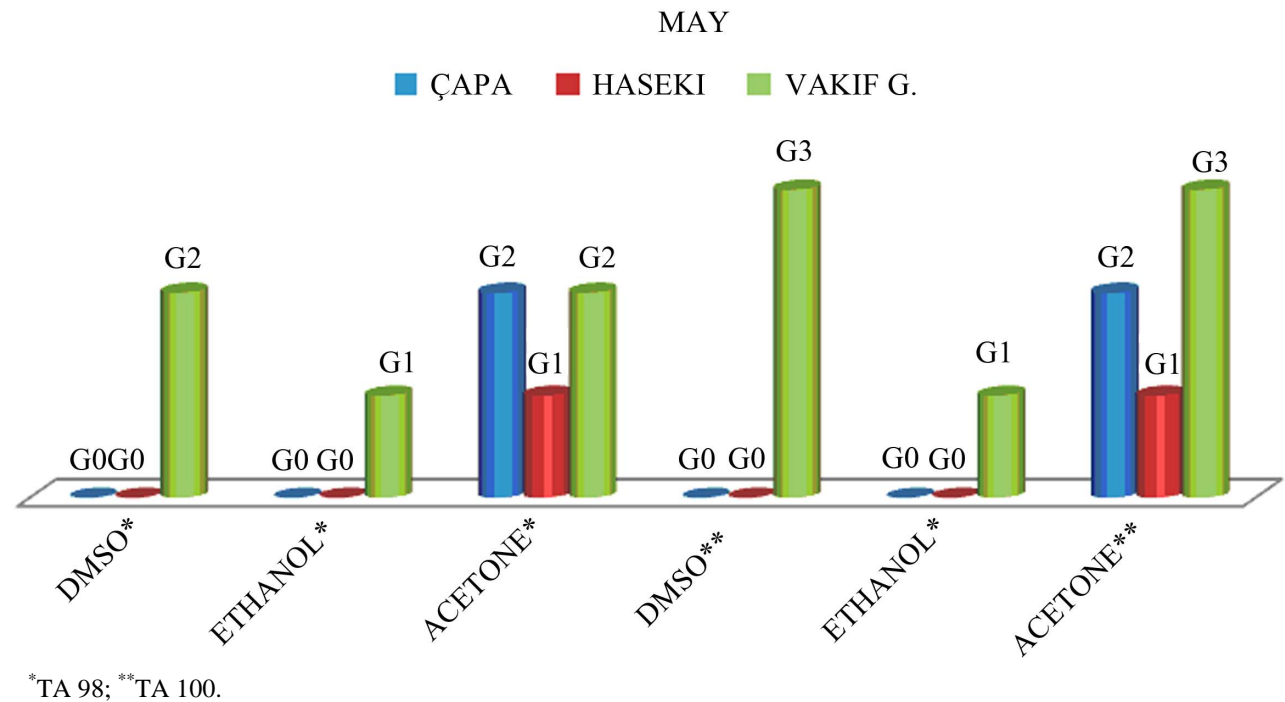

Figure 2. Genotoxicity in May (G0, not genotoxic; G1, slightly genotoxic; G2, moderately genotoxic; G3, strongly genotoxic).

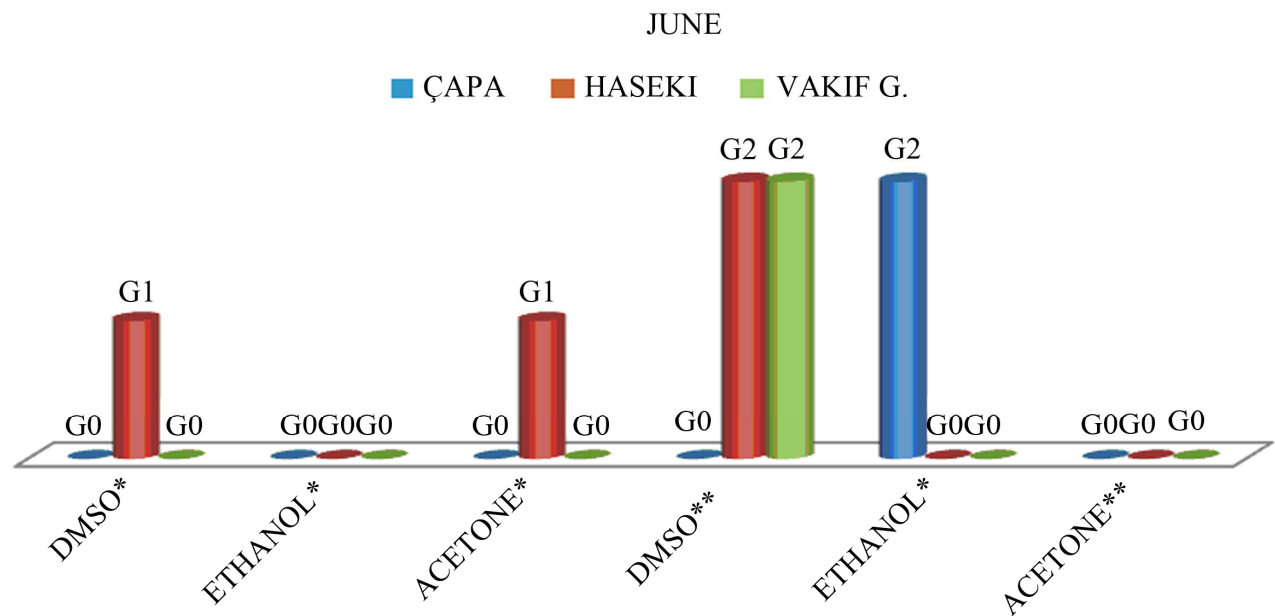

${ }^{*}$ TA $98 ;{ }^{* *}$ TA 100.

Figure 3. Genotoxicity in June (G0, not genotoxic; G1, slightly genotoxic; G2, moderately genotoxic; G3, strongly genotoxic). 
genotoxicity results are given following figures. Generally samples that are solved in acetone more genotoxic than other solvent in TA 98 and samples that are solved in ethanol more genotoxic than other in TA 100.

\section{Discussion}

Wastewater of hospitals contain materials that would be a threat for alive. These water needs to be checked by a biological purification before leaving to nature. Hospital wastewater has differences than domestic waste because of especially blood, body waste, drugs, chemicals, medical device waste and radioactive materials. Chemical or biological agents analyses weren't made cause this study was planned to confirm total pollution of different sources in hospital waste water three powerful solvent materials "DMSO, ethanol and acetone" are used by being inspired from studies in the literature as it is explained detailed in method part $[3,6,18,19]$. It is possible to pass different materials that these solvent chemicals solved from bacteria cell structure and to test by this way.

In present study, that are given Table 2, mutagenic effects of total pollution in hospital wastewater is researched by Salmonella micro some mutagenite test system [6]. Ames method is a method that is used on measuring mutagenic effect of different pollution sources in water sources in the literature [20,21]. These kinds of studies are used in order to confirm mutagenic effect of total pollution of different sources on alive or to investigate pollutions that come from only one source $[4-7,22]$ or to investigate materials that is possible to have mutagenic effects $[9,10]$. According to our result, all of the hospital release mutagenic wastewater to sewage system. March samples more genotoxic than other and June samples generally not toxic because of patient number.
But it is conspicuous that there are many values on limits of mutagenite. In Çapa genotoxicity is found in each 3 solvents in March but it was only seen that mutagenite is available in samples that are solved in acetone in May, mutagenite values are seen only in ethanol in June. In Haseki Hospital all tests that are made in this hospital genotoxicity values are found in all expend one sample in March. In May is samples that are solved in acetone. In Vakıf Gureba Hospital positive results are obtained in samples that are solved in acetone and ethanol in March. It has presented mutagenite in wastewater of hospital especially when patient numbers are more and when it is not rainy.

In studies that are made in some countries, generally some drugs and some pathogen bacteria are researched. In some researching, total genotoxin was checked. In this study, it is first time researched in Turkey that effect on DNA of pollution that is got from water samples from hospital wastewaters. Samples that are taken from 3 hospitals were investigated and total mutagenite was checked in our study.

This study is researched first time in Turkey that effect on DNA of pollution that is got from water samples from hospital wastewaters. Mutagenic effect of pollution that we do not evaluate, cause it is not for our aim, to use adaptation method to mammal systems by adding of S9 system [18] maybe done as a part of routine scanning by results of our study and this will be an important study to see effects and defect of pollution in Istanbul Bosphore. Method constitutes a new approach to check mutagenite of pollution in hospital wastewater. In prospective studies, it is necessary to use this system as a method to monitor mutagenic genotoxic pollution in hospital wastewaters. These kinds of studies present applicability and importance of our method because of placing in the literature [19,23-25].

Table 2. Comparison of different genotoxicity studies on hospital wastewaters [21].

\begin{tabular}{|c|c|c|c|c|c|}
\hline Genotoxicity Studies & Giuliani et al. (1996) & Steger-Hartmann et al. (1997) & Hartmann et al. (1999) & Jolibois et al. (2003) & $\begin{array}{c}\text { Atasoy et al. } \\
2009\end{array}$ \\
\hline Country & Switzerland & Switzerland & Germany & France & Turkey \\
\hline Number of samples & 851 & 6 & 25 & 18 & 108 \\
\hline Sampling time (h) & 1 & 24 & 24 & 10 & 2 \\
\hline Concentration method & No & Yes & No & No & No \\
\hline Genotoxic response (\%) & 13 & 50 & 56 & 55 & 56 \\
\hline Bioassay $^{*}$ & 1 & 1 & 1,2 & 3 & 2 \\
\hline Studied period & $1991-1992$ & 1995 & $1992-1994$ & 2001 & 2009 \\
\hline
\end{tabular}

\footnotetext{
*: 1) umuC; 2) Salmonella test; 3) Salmonella fluctuation test.
} 


\section{REFERENCES}

[1] K. Kuümerer, "Drugs in the Environment: Emission of Drugs Diagnostic Aids and Disinfectants into Wastewater by Hospitals in Relation to Other Sources-A Review," Chemosphere, Vol. 45, 2001, pp. 957-956. doi:10.1016/S0045-6535(01)00144-8

[2] M. Koivusalo, J. J. Jaakkola and T. Vartiainen, "Drinking Water Mutagenicity and Gastrointestinal and Urinary Tract Cancers: An Ecological Study in Finland," American Journal of Public Health, Vol. 84, 1994, pp. 12231228. doi:10.2105/AJPH.84.8.1223

[3] U. Rannug and C. Ramel, "Mutagenicity of Waste Products from Vinly Chloride Industries," Journal of Toxicology and Environmental Health, Vol. 2, No. 5, 1977, pp. 1019-1029. doi:10.1080/15287397709529500

[4] J. L. Epler, J. A. Young, A. A. Hardigree, T. K. Rao, M. R. Guerin, I. B. Rubin, C. H. Ho and B. R. Clark, "Analytical and Biological Analyses of Test Material from the Synthetic Fuel Technologies. I. Mutagenicity of Crude Oils Determined by the S. typhimurium/Microsomal Activation System," Mutation Research, Vol. 57, No. 3, 1979, pp. 265-276. doi:10.1016/0027-5107(78)90211-7

[5] E. R. Netsmann, E. G. Lee, T. I. Matula, G. R. Douglas and J. C. Mueller, "Mutagenicity of Constituents Identified in Pulp and Paper Mill Effluents Using the Salmonella/Mammalian-Micro Some Assay,” Mutation Research, Vol. 79, No. 3, 1981, pp. 203-212.

[6] Y. Manabe, T. Kinouchi, K. Wakiasaka, I. Tahara and Y. Ohnishi, "Mutagenic 1-Nitropyrene in Waste Water from Oil-Water Separating Tanks of Gasoline Stations and in Used Crankcase Oil,” Environmental Mutagen, Vol. 6, No. 5, 1984, pp. 669-681. doi:10.1002/em.2860060505

[7] A. Kamiya and. Y. Ose, "Study of the Behaviour of Mutagens in Waste Water and Emission Gas from a Municipal Incinerator Evaluated by Means of the Ames Assay," Science of the Total Environment, Vol. 65, 1987, pp. 109-120. doi:10.1016/0048-9697(87)90165-3

[8] B. Jolibois and M. Guerbet, "Hospital Wastewater Genotoxicity,” Annals of Occupational Hygiene, Vol. 50, No. 2, 2006, pp. 189-196. doi:10.1093/annhyg/mei051

[9] A. Sundvall, H. Marklund and U. Rannug, "The Mutagenicity on Salmonella typhimurim of Nitrobenzoic Acids and Other Wastewater Compents Generated in the Production of Nitrobenzoic Acids and Nitrotoluenes," $\mathrm{Mu}$ tation Research, Vol. 137, No. 2-3, 1984, pp. 71-78. doi:10.1016/0165-1218(84)90094-6

[10] R. L. Anderson, W. E. Bishop and R. L. Campbell, “A Review of the Environmental and Mammalian Toxicology of Nitrilotriacetic Acid," Critical Reviews in Toxicology, Vol. 15, No. 1, 1985, pp. 1-102. doi:10.3109/10408448509023766

[11] F. Giuliani, T. Koller, F. E. Wurgler, et al., "Detection of Genotoxic Activity in Native Hospital Waste Water by the umuC Test," Mutation Research, Vol. 368, 1996, pp. 49-57. doi:10.1016/S0165-1218(96)90039-7

[12] T. Steger-Hartmann, K. Kümmerer and A. Hartmann, "Biological Degradation of Cyclophosphamide and Its Occurrence in Sewage Water," Ecotoxicology and Envi- ronmental Safety, Vol. 36, 1997, pp. 174-179. doi:10.1006/eesa.1996.1506

[13] A. Hartmann, E. M. Golet, S. Gartisier, et al., "Primary DNA Damage But Not Mutagenicity Correlates with Ciprofloxacin Concentrations in German Hospital Wastewaters," Archives of Environmental Contamination and Toxicology, Vol. 36, 1999, pp. 115-119. doi:10.1007/s002449900449

[14] B. Jolibois, M. Guerbet and S.Vassal, "Detection of Hospital Wastewater Genotoxicity with the SOS Chromotest and Ames Fluctuation Test," Chemosphere, Vol. 51, 2003, pp. 539-543. doi:10.1016/S0045-6535(02)00867-6

[15] J. McCann, N. E. Springarn, J. Kobori and B. N. Ames, "Detection of Carcinogens as Mutagens: Bacterial Tester Strains with R Factor Plasmids," Proceedings of the $\mathrm{Na}$ tional Academy of Sciences, Vol. 75, No. 3, 1975, pp. 979-983.

[16] P. J. Langer, W. G. Shanabruch and G. C. Walker, "Functional Organization of Plasmid pKMlOl," Journal of Bacteriology, Vol. 145, 1981, pp. 1310-1316.

[17] B. J. Dean, T. M. Brooks, G. Hodson-Walker and D. H. Hutson, "Genetic Toxicology Testing of 41 Industrial Chemicals,” Mutation Research, Vol. 153, 1985, pp. 5777. doi:10.1016/0165-1110(85)90005-3

[18] D. Maron and B. N. Ames, "Revised Methods for the Salmonella Mutagenicity Test," Mutation Research, Vol. 113, 1983, pp. 173-215. doi:10.1016/0165-1161(83)90010-9

[19] P. K. Hopke, M. J. Plewa and P. Stapleton, "Reduction of Mutagenicity of Municipal Wastewaters by Land Treatment," Science of the Total Environment, Vol. 66, 1987, pp. 193-202. doi:10.1016/0048-9697(87)90087-8

[20] P. A. White, J. B. Rasmussen and C. Blaise, “Comparing the Presence Potency and Potential Hazard of Genotoxins Exracted from a Broad Range of Industrial Effluents," Environmental and Molecular Mutagenesis, Vol. 27, No. 2, 1996, pp. 116-139. doi:10.1002/(SICI)1098-2280(1996)27:2<116::AID-EM7 $>3.0 . \mathrm{CO} ; 2-\mathrm{E}$

[21] R. G. Stahl, "The Genetic Toxicology of Organic Compounds in Natural Waters and Wastewaters," Ecotoxicology and Environmental Safety, Vol. 22, 1991, pp. 94-125. doi:10.1016/0147-6513(91)90051-P

[22] U. Rannug and C. Ramel, "Mutagenicity of Waste Products from Vinly Chloride Industries," Journal of Toxicology and Environmental Health, Vol. 2, No. 5, 1977, pp. 1019-1029. doi:10.1080/15287397709529500

[23] W. K. De-Raat, A. O. Hanstveit and. J. K. De-Kreuk, "The Role of Mutagenicity Testing in the Ecotoxicological Evaluation of Industrial Dicharges into the Aquatic Environment," Food and Chemical Toxicology, Vol. 23, No. 1, 1985, pp. 33-41. doi:10.1016/0278-6915(85)90217-0

[24] S. Kotelevtsev, V. Kozlov, P. Iu and L. I. Stepanova, "Ecological and Toxicological Control over the Status of the Environment by the Methods of Physicochemical Biology," Nauchnye Doklady Vyssher Shkoly, Biologicheskie Nauki, Vol. 1, 1986, pp. 19-30. 
[25] N. Cerna, V. Hajek, E. Stejskalova, L. Dobias, Z. Zudova and P. Rossner, "Environmental Genotoxicity Monitoring Using S. typhimurium Strains as
Indicator System," Science of the Total Environment, Vol. 101, No. 1-2, 1991, pp. 139-147. doi:10.1016/0048-9697(91)90113-S 